\title{
Phylogeography of the European roe deer Capreolus capreolus as revealed by sequence analysis of the mitochondrial Control Region
}

\author{
Jens WIEHLER and Ralph TIEDEMANN*
}

Wiehler J. and Tiedemann R. 1998. Phylogeography of the European roe deer Capreolus capreolus as revealed by sequence analysis of the mitochondrial Control Region. [In: Ecological genetics in mammals III. G. B. Hartl and J. Markowski, eds]. Acta Theriologica, Suppl. 5: 187-197.

To assess levels of genetic variation as well as the genetic differentiation among populations, 40 roe deer Capreolus capreolus (Linnaeus, 1758) from 8 European populations were analysed with regard to DNA sequence variation at the highly polymorphic part I of the mitochondrial Control Region. DNA was extracted from liver samples, a $480 \mathrm{bp}$ sequence was amplified via PCR and subsequenctly sequenced, yielding $427 \mathrm{bp}$ scorable DNA sequence. A total of 22 polymorphic sites were found, defining 19 mitochondrial haplotypes. Levels of overall genetic variation were high with regard to haplotype diversity $(\delta=0.94)$ and moderate with regard to nucleotide diversity $(\pi=0.97 \%)$, as compared to other mammalian species. This is indicative of a large present effective population size $\left(N_{e}\right)$ and a former population bottleneck, presumably during the last Pleistocene glaciation. The Norwegian roe deer population appeared to be monomorphic, presumably as an effect of the very recent colonization of Norway by roe deer. Among the central European populations studied, there is a significant correlation between net nucleotide diversity and geographic distance among populations. On the contrary, Nei distances derived from allozyme data of a previous investigation on the same specimens did not show any correlation with geographic distance. It is assumed, that maternal gene flow is restricted due to female philopatry, while nuclear gene flow is pronounced due to male dispersal. A phylogenetic analysis of mitochondrial haplotype relationships revealed two groups of haplotypes with an uneven geographic distribution. One possible explanation is the existence of two separate Pleistocene refugia, where different mitochondrial lineages might have survived. Another possible scenario is one single refugium in Western Europe with a subsequent postglacial recolonization of the continent from West to East. Patterns of nucleotide diversity $(\pi)$ and the assumed phylogeny of Eastern European mitochondrial haplotypes provide some evidence for the latter hypothesis. However, a more thorough analysis is needed both to accurately estimate levels of genetic variation and to settle the presumable phylogeography of roe deer in Europe.

Institut für Haustierkunde, Christian-Albrechts-Universität zu Kiel, Olshausenstraße 40, D-24118 Kiel, Germany

Key words: Capreolus capreolus, isolation-by-distance, gene flow, Pleistocene bottleneck

* To whom correspondence should be addressed. 


\section{Introduction}

The European roe deer Capreolus capreolus (Linnaeus, 1758) is coherently distributed over Europe (cf Lehmann and Sägesser 1986). The overall population size has been estimated to 3.8 million individuals (Pielowski 1977), which might even be an underestimation (Kurt 1991). As a game species, roe deer populations have been significantly influenced by human activities, such as hunting, feeding, and translocation. Especially translocation and selective hunting, eg for antler characters, might heavily influence the genetic integrity of populations, as has been demonstrated in other large mammals (translocation in Asian elephant Elephas maximus, Hartl et al. 1996; antler selection in red deer Cervus elaphus, Hartl et al. 1995). Additionally, genetic exchange among local populations may be frequently hindered by human infrastructure (roads, buildings etc). Moreover, the large overall population size is a relatively new phenomenon. The increase in number had been recognized about two centuries ago. It might have been caused by the increase of agricultural areas or the decrease in number of both possible competitors (ie red deer) and carnivorous species (cf Kurt 1991). Thus, long-term effective population sizes might be considerably smaller than those expected from actual census data.

The degree of local genetic differentiation is influenced by the dispersal behaviour. In roe deer, as in many cervid species, male dispersal and female philopatry is the rule. The gene flow among adjacent populations due to migrating males often prevents a pronounced differentiation in nuclear encoded characters, as has already been demonstrated in roe deer (Hartl et al. 1991, 1993).

Provided that females are philopatric, we expect the maternally inherited mitochondrial DNA to yield a better phylogeographic resolution of population history and differentiation than nuclear genes. Aiming at a description of population divergence as well as at an estimation of levels of genetic variation in European roe deer, we investigated the sequence variation at part I of the mitochondrial DNA Control Region which is known to be highly polymorphic in many vertebrates (eg Vigilant et al. 1991).

\section{Material and methods}

A total of 40 roe deer were examined, 5 from each of 8 different European localities (Fig. 1). For most of the examined individuals, allozyme variability has been investigated in previous studies (Hartl et al. 1991, 1993, Gmeiner 1994). Total DNA was extracted from $0.1 \mathrm{~g}$ of liver using the SuperQuikGene DNA isolation kit (Analytical Genetic Testing Center, Denver). About 480bp from the 3'-end of the mitochondrial Control Region were amplified using the primers 5-CACCACCAACACCCAAAGCT-3' and 5-CCTGAAGTAAGAACCAGATG-3' (Tiedemann et al. 1996b). Amplification was carried out for 40 cycles of $94^{\circ} \mathrm{C}(1: 30 \mathrm{~min}), 58^{\circ} \mathrm{C}(1: 15 \mathrm{~min})$, and $72^{\circ} \mathrm{C}(1: 30 \mathrm{~min})$. PCR-products were directly sequenced using the Sequitherm Cycle Sequencing kit (Epicentre, Madison) and the Digoxigenin-labelled primer 5 -DIG-CACCAACACCCAAAGCT at $95^{\circ} \mathrm{C}(30 \mathrm{~s}), 53.2^{\circ} \mathrm{C}(1: 15 \mathrm{~min})$, and $72^{\circ} \mathrm{C}(1: 30$ $\mathrm{min}$ ) for 30 cycles. Samples were run on a direct blot sequencing device (Hoefer, San Francisco) and detected via chemiluminescence (Richterich et al. 1989). 
Fig. 1. Sampling localities of the roe deer specimens studied (A - Austria, Bg - Bulgaria, F - France, I - Italy, N - Norway, Pl - Poland, Slo - Slovenia, Sk - Slovakia).

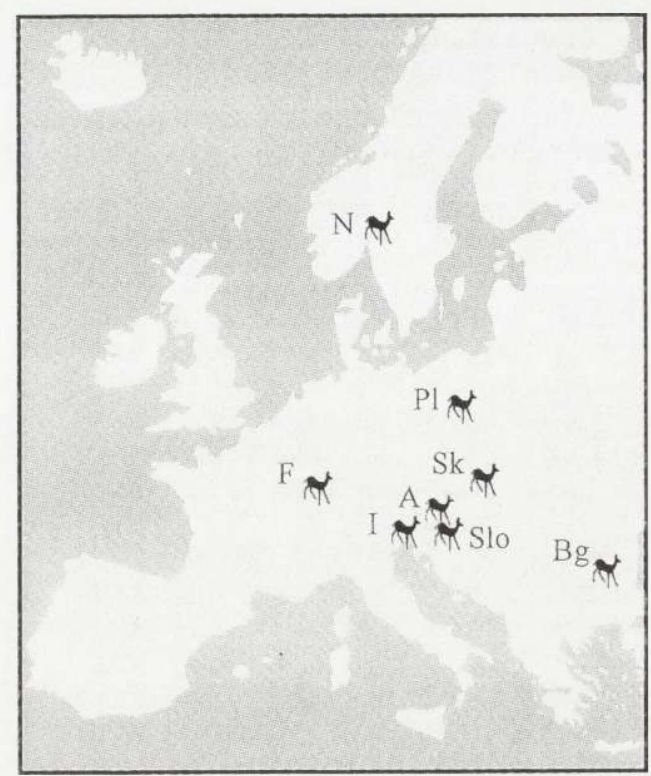

Mitochondrial haplotypes were defined on the basis of $427 \mathrm{bp}$ scored sequence. Pairwise nucleotide divergence as well as intra- and interpopulation nucleotide diversities $(\pi)$ were calculated according to Quinn and White (1987). Haplotype diversities $(\delta)$ were estimated according to Nei and Tajima (1981). The molecular variance was assigned to intra- vs. interpopulation differentiation using the computer program AMOVA 1.55 (Excoffier et al. 1992). Using the PHYLIP 3.5c computer package (Felsenstein, 1993), a Maximum-Likelihood-tree was constructed and a parsimony analysis was performed. From the most parsimonious trees, a consensus tree was derived.

\section{Results}

The 40 analyzed specimens comprised 19 mitochondrial haplotypes defined by 22 polymorphic sites, of which one was a transversion and 21 were transitions

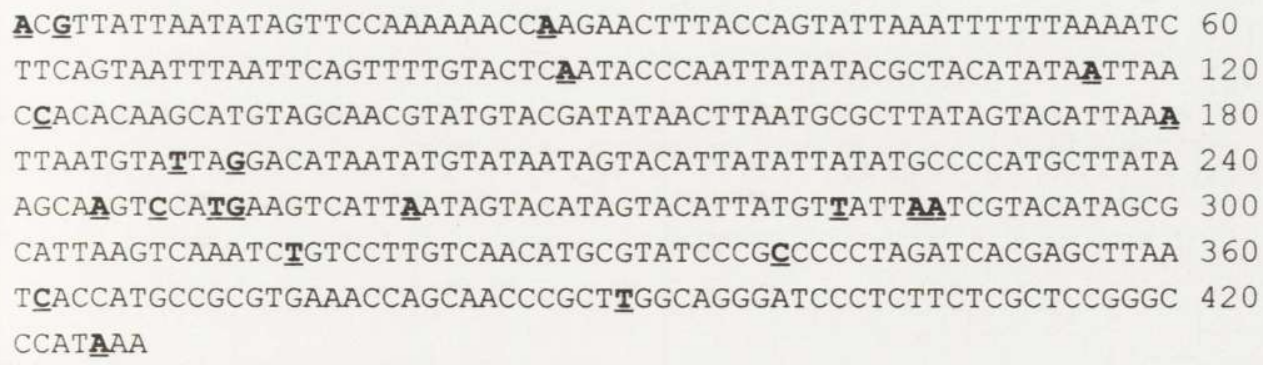

Fig 2. Control Region part I sequence of the roe deer haplotype I. Positions polymorphic among the analysed individuals are underlined. 


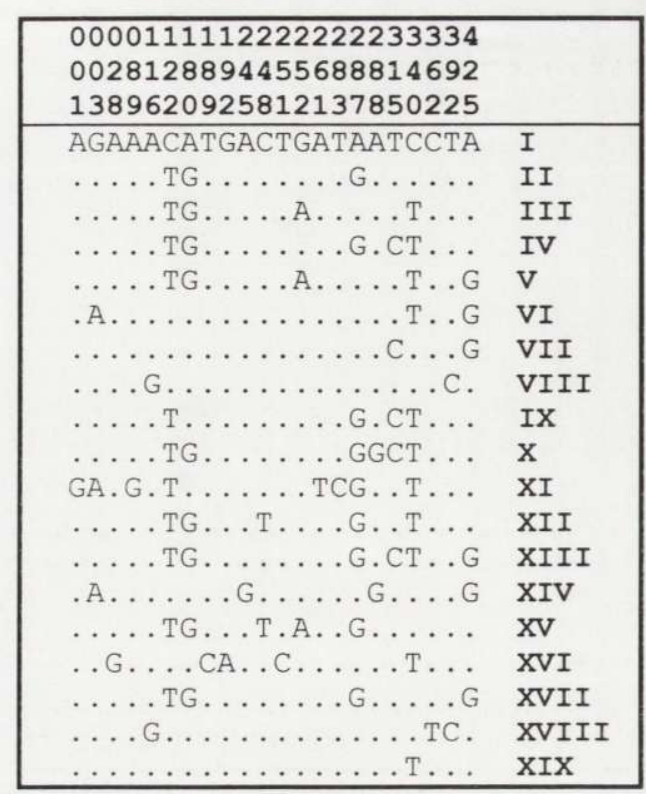

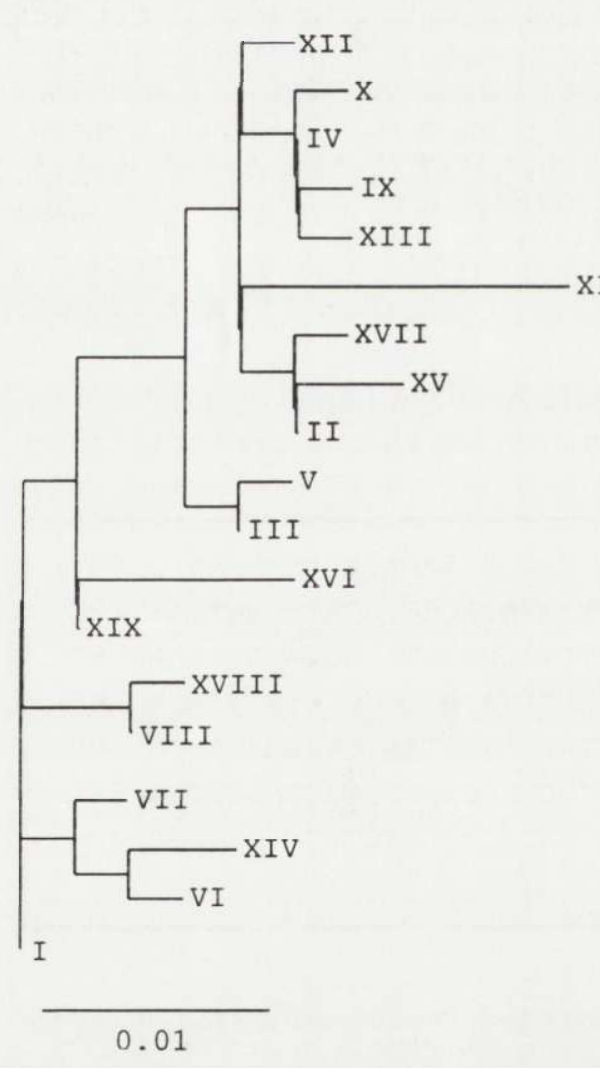

Fig. 3. Sequence polymorphisms in the mitochondrial haplotypes I-XIX found in roe deer in this study. Position numbers are indicated by three vertical digits and refer to Fig. 2.

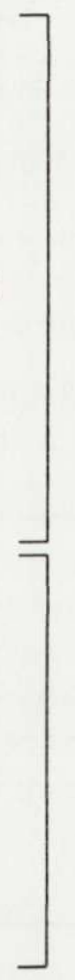

W

$E$

Fig. 4. Maximum-Likelihood-tree of the roe deer mitochondrial haplotypes. (Assumed transition: transversion ratio was $10: 1)$. W - "western" haplotype, E "Eastern" haplotype. 
Table 1 . Haplotype frequency, nucleotide diversity $(\pi)$, and haplotype diversity $(\delta)$ within roe deer populations. Additionally, the expected heterozygosity $\left(H_{e}\right)$ of a previous allozyme study on the same samples is given, where available (Gmeiner 1994). F - France, A - Austria, I - Italy, Slo - Slovenia, $\mathrm{Pl}$ - Poland, Sk - Slovakia, Bg - Bulgaria, N - Norway.

\begin{tabular}{|c|c|c|c|c|c|c|c|c|}
\hline & $\mathrm{F}$ & A & I & Slo & $\mathrm{Pl}$ & Sk & $\mathrm{Bg}$ & $\mathrm{N}$ \\
\hline \multicolumn{9}{|c|}{ Haplotypes (absolute frequency) } \\
\hline & $\begin{array}{l}\text { II (1) } \\
\text { IX (1) } \\
\text { X (1) } \\
\text { XI (1) } \\
\text { XII (1) }\end{array}$ & $\begin{array}{l}\text { I (2) } \\
\text { III (2) } \\
\text { VII (1) }\end{array}$ & $\begin{array}{l}\text { III (2) } \\
\text { V (1) } \\
\text { VII (1) } \\
\text { XIII (1) }\end{array}$ & $\begin{array}{l}\text { I (3) } \\
\text { XIV (1) } \\
\text { XV (1) }\end{array}$ & $\begin{array}{l}\text { IV (3) } \\
\text { XVI (1) } \\
\text { XVII (1) }\end{array}$ & $\begin{array}{l}\text { IV (1) } \\
\text { V (1) } \\
\text { VI (3) }\end{array}$ & $\begin{array}{l}\text { I (1) } \\
\text { VIII (2) } \\
\text { XVIII (1) } \\
\text { XIX (1) }\end{array}$ & II (5) \\
\hline$\pi(\%)$ & 0.82 & 0.60 & 0.64 & 0.67 & 0.79 & 0.64 & 0.37 & 0.00 \\
\hline$\delta$ & 1.00 & 0.80 & 0.90 & 0.70 & 0.70 & 0.70 & 0.90 & 0.00 \\
\hline$H_{e}$ & 0.041 & 0.036 & - & 0.062 & 0.036 & 0.057 & 0.069 & - \\
\hline
\end{tabular}

(Figs 2, 3). In a Maximum-Likelihood-tree (Fig. 4), the haplotypes could be assigned to two groups, of which one (W) was more frequently found in western areas, while the other (E) had a more eastern distribution (Table 1). The topology of the Maximum-Likelihood-tree including the definition of the two groups of haplotypes were confirmed in the parsimony consensus tree (Fig. 5). Apart from the Norwegian sample which was monomorphic, nucleotide diversities $(\pi)$ within populations ranged from $0.37 \%$ to $0.82 \%$ and haplotype diversities ranged from 0.70 to 1.00 (Table 1 ). The overall nucleotide diversity was $0.97 \%$, the overall haplotype diversity was 0.94 . Net nucleotide diversities among populations are given in Table 2. The distribution of the two groups of haplotypes $\mathrm{W}$ and $\mathrm{E}$ among

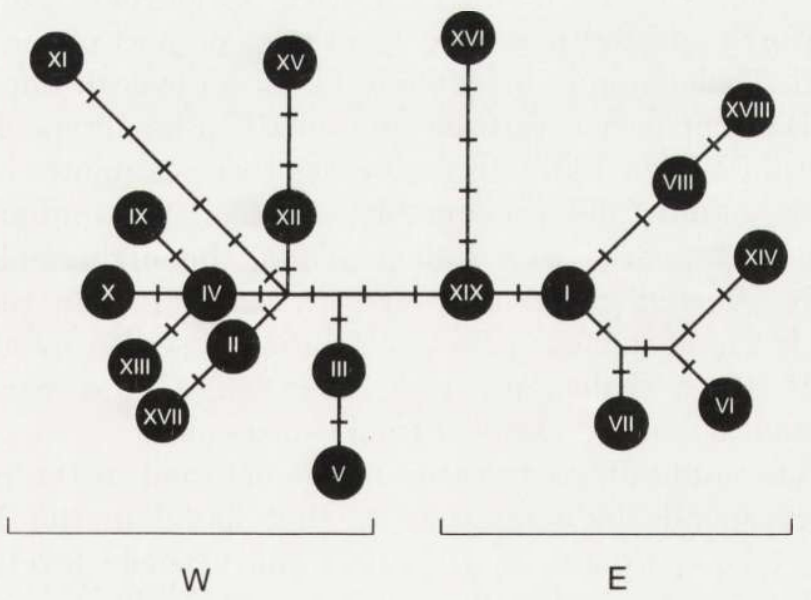

Fig. 5. Parsimonious network of mitochondrial haplotypes in roe deer. Abbreviations are given in Fig. 4. 
Table 2. Estimates of net nucleotide diversity among populations (below diagonal). Additionally, Rogers distance among populations from a previous allozyme study on the same samples are given, where available (above diagonal; from Gmeiner 1994). Abbreviations are given in Table 1.

\begin{tabular}{lcccccccc}
\hline & F & A & I & Slo & Pl & Sk & Bg & N \\
\hline F & - & 0.063 & - & 0.065 & 0.046 & 0.048 & 0.079 & - \\
A & 0.49 & - & - & 0.093 & 0.058 & 0.087 & 0.090 & - \\
I & 0.40 & 0.18 & - & - & - & - & - & - \\
Slo & 0.59 & 0.12 & 0.47 & - & 0.081 & 0.042 & 0.054 & - \\
Pl & 0.15 & 0.37 & 0.25 & 0.57 & - & 0.082 & 0.090 & - \\
Sk & 0.52 & 0.27 & 0.22 & 0.41 & 0.42 & - & 0.063 & - \\
Bg & 0.92 & 0.32 & 0.78 & 0.27 & 0.84 & 0.67 & - & - \\
N & 0.29 & 0.50 & 0.52 & 0.51 & 0.31 & 0.81 & 0.89 & - \\
\hline
\end{tabular}

populations was highly significantly heterogenous $\left(\chi^{2}\right.$-heterogeneity test; $\chi^{2}=$ 20.358; $p=0.0048$ ). According to the analysis of molecular variance (AMOVA), $21 \%$ of the genetic variation can be attributed to differentiation among populations, while the remaining $79 \%$ reflect intrapopulation variance.

\section{Discussion}

Sequence variation in the mitochondrial Control Region of roe deer

Comprising 19 different haplotypes in a sample of only 40 specimens and a haplotype diversity $(\delta)$ of 0.94 , the mitochondrial Control Region in roe deer proved to be highly diverse. Similarily high haplotype diversities have been found in comparable studies, when populations with a presumably high effective population size $\left(N_{e}\right)$ were investigated (eg $\delta=0.99$ for the human population of Turkey, calculated from Comas et al. 1996). In a study on harbour porpoise Phocoena phocoena from North and Baltic Sea, where the same part of the Control Region was investigated, Tiedemann et al. (1996b) found an overall haplotype diversity of 0.80 , and in Harbour porpoises from around UK a haplotype diversity of only 0.59 was described (Walton 1997). In both cases these estimates are corroborated by much smaller actual (and presumably effective) population sizes of these populations, when compared to roe deer. Thus, the high haplotype diversity indicates a large effective population size $\left(N_{e}\right)$ in European roe deer. This is consistent with levels of nuclear genetic variation assessed by allozyme studies (Hartl et al. 1991, 1993, Tiedemann et al. 1996a) and is also corroborated by the large actual population size as derived from census data.

The overall nucleotide diversity $(\pi)$ of $0.97 \%$ detected in the present study is moderate. It corresponds in magnitude to that found in the Turkish human population ( $\pi=0.88 \%$, Comas et al. 1996) and exceeds levels of $\pi$ in some presumably bottlenecked populations (eg sperm whale Physeter macrocephalus: $\pi=0.38 \%$, Lyrholm et al. 1996; harbour porpoise in North and Baltic Sea: 
$\pi=0.37 \%$, Tiedemann et al. 1996b). However, considerably higher nucleotide diversities for the analysed part of the Control Region have been found in some mammals: In the humpback whale Megaptera novaeangliae, intra-ocean nucleotide diversities range from 1.35 to 2.29\% (Baker et al. 1993), and for the Grant gazelle Gazella granti in Kenya a nucleotide diversity of $14 \%$ was reported (Arctander et al. 1996). As compared to these values, the lower $\pi$ in European roe deer might be indicative of a former population bottleneck ( $\mathrm{cf}$ Kurt 1991).

\section{Genetic differentiation within and among roe deer populations}

Among the European roe deer populations, the Norwegian one is peculiar in that it exhibits no genetic variation in the analysed sample set. A possible explanation is the extinction of roe deer in most parts of Scandinavia including Norway during the 19th century and a very recent recolonization of Norway during this century (cf Lehmann and Sägesser 1986). Thus, the lack of genetic variation most probably indicates a founder effect.

Apart from the Norwegian population, the most variable population was the French one with $\pi=0.82 \%$ and $\delta=1.00$, while the more eastern populations tended to exhibit less variation with regard to the mitochondrial Control Region (cf Table 1). However, there was no significant correlation between $\pi$ - and $\delta$-values $(r=-0.08 \mathrm{~ns})$. Additionally, there was no significant correlation between the measures of mitochondrial genetic variation $(\pi$ and $\delta$ ) and a measure of nuclear genetic variation, the expected heterozygosity $H_{e}\left(r=-0.69\right.$ for $\pi$ vs $H_{e} ; r=-0.04$ for $\delta$ vs $H_{e} ; H$ e values derived from an allozyme study by Gmeiner 1994). The latter might be explained by sex differences in dispersal: Since mitochondrial DNA is only maternally inherited, its variation is affected by the female effective population size $\left(N_{e(f)}\right)$. For a local population, $N_{e(f)}$ can be small in the case of female philopatry as in the roe deer. The effective population size with regard to nuclear genes $\left(N_{e}\right)$ can be considerably larger, depending on the adopted mating system (eg Apollonio and Hartl 1993) and the migration behaviour of males.

Due to the peculiar inheritance mode of mitochondrial DNA in combination with female philopatry, more pronounced divergence among populations should be expected in mitochondrial DNA than in nuclear DNA (cf Avise 1994). Indeed, the analysis of molecular variance (AMOVA) assigned a significant proportion of $21 \%$ of the total genetic variation to divergence among populations of roe deer, while a study on nuclear encoded allozymes assigned only $10 \%$ of the total variation to divergence among populations (Hartl et al. 1991).

The net nucleotide divergence among populations (cf Table 2) showed a highly significant correlation with the approximate geographic distance between the respective localities $(r=0.66, p=0.007$; Fig. 6$)$, clearly indicating limited maternal gene flow and isolation-by-distance among the roe deer populations. On the contrary, nuclear genetic divergence was not correlated with geographic distance (Fig. 6). Thus, we conclude that there is considerable gene flow among nuclear 

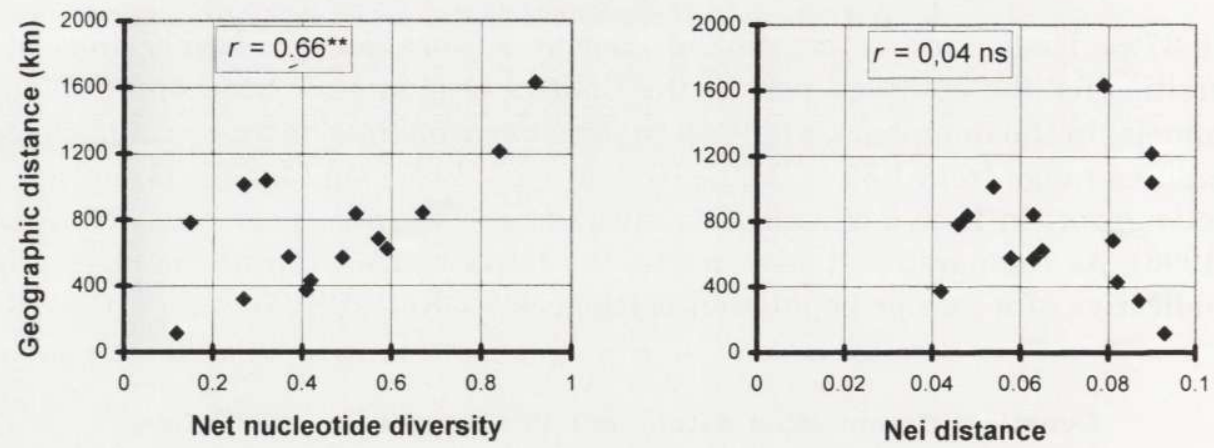

Fig. 6. Left: Correlation of net nucleotide diversity among roe deer populations and their geographic distance. Right: Correlation of Nei distance among roe deer populations and their geographic distance (based on allozyme variation; data from Gmeiner 1994). ${ }^{* *}-p<0.01$, ns - not significant.

gene pools of the roe deer populations, presumably due to migrating males, while maternal gene flow is limited.

\section{Relationships among mitochondrial haplotypes}

Both Maximum Likelihood and parsimony analysis divided the described haplotypes into two groups. The eastern group (E) comprises the most abundant and widespread haplotype, type I (cf Table 1, Figs 4, 5). Since this type is at a central position within its group, it might represent an ancestral state. The star-like phylogeny within the E group of haplotypes with an abundant central and less abundant peripheral types indicates a recent population expansion (Avise et al. 1984), as has been shown in several mammalian species (eg harbour seal Phoca vitulina, Stanley et al. 1996; harbour porpoise, Rosel et al. 1998). Among the Western haplotypes (W), the most widespread and abundant haplotype was type IV, again near the centre of the W-group of haplotypes (Fig. 5).

\section{Phylogeography of Central European roe deer populations}

The distribution of the two described groups of haplotypes showed pronounced geographic differences. A geographical gradient in the respective frequencies of the two groups could be detected (Fig. 7). One possible explanation is a former geographic separation of the two lineages, possibly due to the existence of two different refugia during the last Pleistocene glaciation, when roe deer populations were restricted to the mediterranean area (Lehmann and Sägesser 1986). From a south western and a south eastern refugium, recolonization might have occured. In central Europe, both lineages might have met again, resulting in a mixture of haplotypes of the two lineages (Fig. 7).

However, a different scenario can also be developed: If we assume only one refugium during the last glaciation, we could expect the highest level of genetic variation in the population located most closely to this refugium, with a steady decrease with geographic distance due to subsequent founder effects. The founding 
Fig. 7. Relative frequency of mitochondrial haplotypes of the Western type (W) in the analysed roe deer populations.

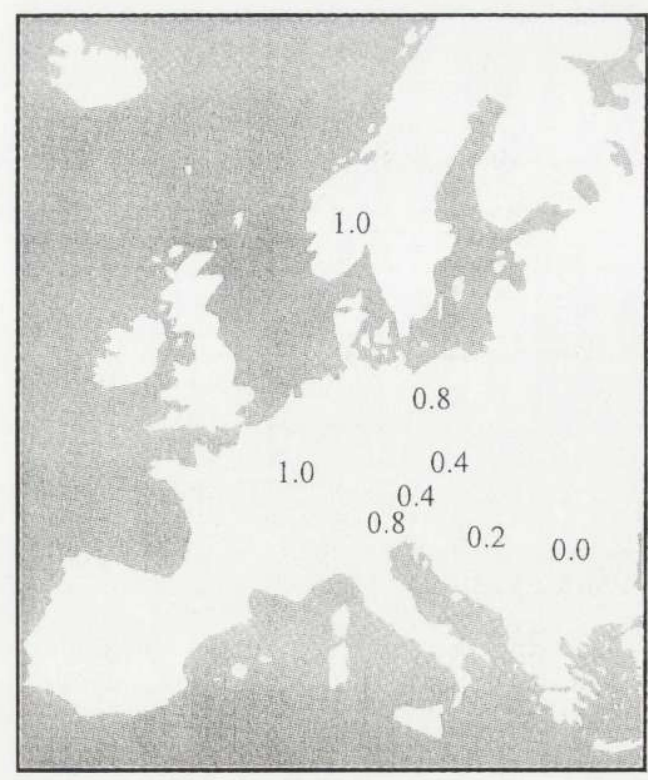

events would likely have caused a severe depletion of mitochondrial genetic variation, ultimately leading to the fixation of one mitochondrial haplotype in some populations. Given a population expansion after the bottleneck, we should expect a star-like phylogeny of haplotypes with an abundant central, presumably ancestral haplotype (see above), as is indeed found in the Eastern Group of roe deer haplotypes. In this scenario, we would expect haplotype diversity $(\delta)$, which is not affected by sequence divergence among haplotypes, to be more quickly regained in the formerly bottlenecked populations than nucleotide diversity $(\pi)$. A comparison of the westernmost (France) and the easternmost (Bulgaria) population as to measures of mitochondrial genetic variation reveals a similar level of $\delta$ (1.00 vs 0.90 ; cf Table 1$)$, but a remarkable difference in $\pi(0.82 \%$ vs $0.37 \%)$. In the framework of the above consideration, this may suggest a single late Pleistocene refugium which then should be located in the Western part of Europe, presumably near the mediterranean sea (Lehmann and Sägesser 1986). If we plot the measures of mitochondrial genetic variation of the population along the trajectory from France to Bulgaria (Fig. 8), we see a significant decrease in $\pi$-values, while $\delta$-values have a minimum at intermediate populations (Slovenia, Slovakia). The $\pi$-values together with the pronounced star-like phylogeny of eastern haplotypes might thus be indicative of a subsequent postglacial recolonization from West to East, while the $\delta$-values might rather reflect extant effective population sizes $N_{e}$, which might be lower around the Alps (Slovenia, Northern-Italy, Austria) than in France or Bulgaria. A colonization from a single refugium would also easily explain the congruence of geographic distance and genetic divergence, which has been demonstrated above (cf Figs 6, 7). 


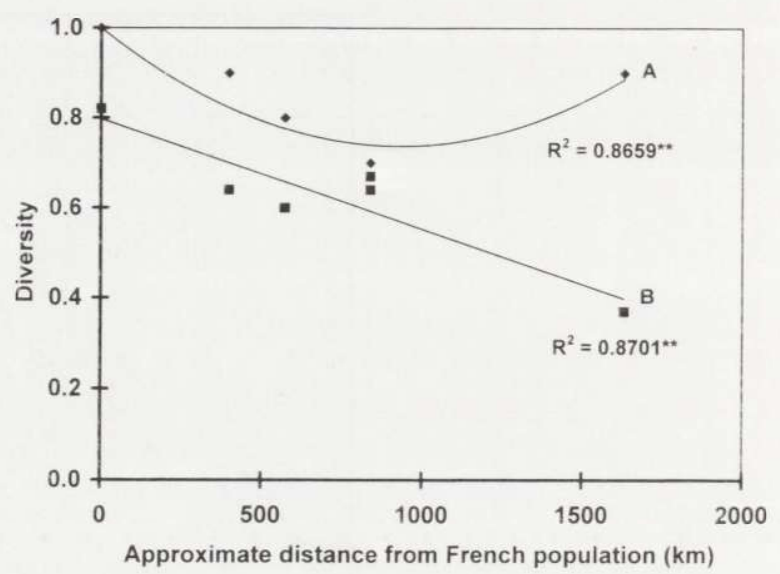

Fig. 8. Haplotype diversity (A) and nucleotide diversity (B; in \%) in the roe deer populations along the trajectory France-Bulgaria (Norway and Poland excluded) plotted against their geographical distance from the French population. Regressions are quadratic for A and linear for B.

However, it should be pointed out, that the limited sample size of the present study is a drawback of the above consideration. Thus, estimates of genetic variation must be considered preliminary. To fully elucidate the phylogeography of European roe deer, a more thorough analysis is needed, which should also include specimens from the Iberian peninsula, which might has served as a late Pleistocene refugium for European roe deer.

Acknowledgements: We are indebted to Prof G. B. Hartl for supervising the study, providing the samples, and critically reviewing the manuscript.

\section{References}

Apollonio M. and Hartl G. B. 1993. Are biochemical-genetic variation and mating systems related in large mammals? [In: Ecological genetics in mammals. G. B. Hartl and J. Markowski, eds]. Acta Theriologica 38, Suppl. 2: 175-185.

Arctander P., Kat P. W., Aman R. A. and Siegismund H. R. 1996. Extreme genetic differences among populations of Gazella granti, Grant's gazelle in Kenya. Heredity 76: 465-475.

Avise J. C., Neigel J. E. and Arnold J. 1984. Demographic influences on mitochondrial DNA lineage survivorship in animal populations. Journal of Molecular Evolution 20: 99-105

Avise J. C. 1994. Molecular markers, natural history and evolution. Chapman and Hall, New York, London: 1-511.

Baker C. S., Perry A., Bannister J. L., Weinrich M. T., Abernethy R. B., Calambokidis J., Lien J., Lambertsen R. H., Ramírez U., Vasquez O., Clapham P. J., Alling A., O’Brien S. J. O. and Palumbi S. R. 1993. Abundant mitochondrial DNA variation and world-wide population structure in humpback whales. Proceedings of the National Academy of Science USA 90: 8239-8243.

Comas D., Calafell F., Mateu E., Pérez-Lezaun A. and Bertranpetit J. 1996. Geographic variation in human mitochondrial DNA Control Region sequence: the population history of Turkey and its relationship to the European populations. Molecular Biology and Evolution 13: 1067-1077. 
Excoffier L., Smouse P. E. and Quattro J. M. 1992. Analysis of molecular variance inferred from metric distances among DNA haplotypes: application to human mitochondrial DNA restriction data. Genetics 131: 479-491.

Felsenstein J. 1993. Phylip (Phylogeny Inference Package) version 3.5c. Department of Genetics, University of Washington, Seatle.

Gmeiner C. 1994. Biochemisch-genetische Variabilität und ihre Einflußfaktoren beim mitteleuropäischen Reh (Capreolus capreolus L.). Unpublished Diploma thesis, Veterinary University of Vienna, Vienna: 1-52.

Hartl G. B., Reimoser F., Willing R. and Köller J. 1991. Genetic variability and differentiation in roe deer (Capreolus capreolus) of Central Europe. Genetics, Selection, Evolution 23: 281-299.

Hartl G. B., Markov G., Rubin A., Findo S., Lang G. and Willing R. 1993. Allozyme diversity within and among populations of three ungulate species (Cervus elaphus, Capreolus capreolus, Sus scrofa) of Southeastern and Central Europe. Zeitschrift für Säugetierkunde 58: 352-361.

Hartl G. B., Klein F., Willing R., Apollonio M. and Lang G. 1995. Allozymes and the genetics of antler development in red deer (Cervus elaphus). Journal of Zoology, London 237: 83-100.

Hartl G. B., Kurt F., Tiedemann R., Gmeiner C., Nadlinger K., Khyne U Mar and Rübel A. 1996 Conservation genetics and systematics of Asian elephant (Elephas maximus): A study based on sequence variation at the Cyt $b$ gene of PCR-amplified mitochondrial DNA from hair bulbs. Zeitschrift für Säugetierkunde 61: 285-294.

Kurt F. 1991. Das Reh in der Kulturlandschaft. Veriag Paul Parey, Hamburg, Berlin: 1-284.

Lehmann E. v. and Sägesser H. 1986. Capreolus capreolus Linnaeus, 1758 - Reh. [In: Handbuch der Säugetiere Europas, Band 2/II Paarhufer. J. Niethammer and F. Krapp, eds]. Aula Verlag, Wiesbaden: 233-268.

Lyrholm T., Leimar O. and Gyllensten U. 1996. Low diversity and biased substitution patterns in the mitochondrial Control Region of Sperm whales: Implications for estimates of time since common ancestry. Molecular Biology and Evolution 13: 1318-1326.

Nei M. and Tajima F. 1981. DNA polymorphism detectable by restriction endonucleases. Genetics 97 : $145-163$.

Pielowski Z. 1977. Das Feldreh - Wild der Zukunft in der Agrarlandschaft. [In: Beiträge zur Jagdund Wildforschung Band 10. H. Stubbe, ed]. VEB Deutscher Landwirtschaftsverlag, Berlin: $193-200$

Quinn T. W. and White B. N. 1987. Analysis of DNA sequence variation. [In: Avian genetics. F. Cooke and P. A. Buckley, eds]. Academic Press, London: 163-198.

Richterich P., Heller C., Wurst H. and Pohl F. M. 1989. DNA sequencing with direct blotting electrophoresis and colorimetric detection. BioTechniques 7: 52-58.

Rosel P. E., Tiedemann R. and Walton M. 1998. Genetic evidence for restricted trans-Atlantic movements of the harbour porpoise, Phocoena phocoena. Marine Biology (in press).

Stanley H. F., Casey S., Carnahan J. M., Goodman S., Harwood J. and Wayne R. K. 1996. Worldwide patterns of mitochondrial DNA differentiation in the harbor seal (Phoca vitulina). Molecular Biology and Evolution 13: 368-382.

Tiedemann R., Hammer S., Suchentrunk F. and Hartl G. B. 1996a. Allozyme variability in medium-sized and large mammals: determinants, estimators, and significance for conservation. Biodiversity Letters 3: 81-91.

Tiedemann R., Harder J., Gmeiner C. and Haase E. 1996b. Mitochondrial DNA sequence patterns of Harbour porpoises (Phocoena phocoena) from the North and the Baltic Sea. Zeitschrift für Säugetierkunde 61: 104-111.

Vigilant L., Stoneking M., Harpending H., Hawkes K. and Wilson A. C. 1991. African populations and the evolution of human mitochondrial DNA. Science 253: 1503-1507.

Walton M. 1997. Population structure of harbour porpoises Phocoena phocoena in the seas around the UK and adjacent waters. Proceedings of the Royal Society, London, Series B 264: 89-94.

Received 23 March 1998, accepted 30 April 1998. 